\title{
Assessing Drivers of Infrastructure Delivery at the Metropolitan, Municipal and District Assemblies (MMDAs) in Ghana
}

\author{
Joe Kingsley Hackman, Joshua Ayarkwa, Dickson Osei-Asibey*, Theophilus Adjei-Kumi, \\ Alex Acheampong, Godslove Ampratwum
}

Department of Construction Technology and Management, Kwame Nkrumah University of Science and Technology (KNUST), Kumasi, Ghana

Email: *dicksonosei-asibey@gmail.com

How to cite this paper: Hackman, J. K., Ayarkwa, J., Osei-Asibey, D., Adjei-Kumi, T., Acheampong, A., \& Ampratwum, G. (2021). Assessing Drivers of Infrastructure Delivery at the Metropolitan, Municipal and District Assemblies (MMDAs) in Ghana. Open Journal of Social Sciences, 9, 69-85. https://doi.org/10.4236/jss.2021.96008

Received: May 1, 2021

Accepted: June 7, 2021

Published: June 10, 2021

Copyright $\odot 2021$ by author(s) and Scientific Research Publishing Inc. This work is licensed under the Creative Commons Attribution International License (CC BY 4.0).

http://creativecommons.org/licenses/by/4.0/

\begin{abstract}
This paper aimed at assessing drivers of infrastructure delivery at the Metropolitan, Municipal and District Assemblies (MMDAs) in Ghana. The study followed the quantitative research approach. One hundred and twenty-one professionals (121) from thirty-six (36) MMDAs in the Greater Accra and Ashanti Regions of Ghana participated in a questionnaire survey. Mean Scores and One Sample t-test were used for the analysis of the data. The findings suggest that 10 factors listed as "effective managerial skills and proper supervision", "political commitment of central government", "effective communication", "attention to developing appropriate local authority procurement system", "proper cost budgeting", "checking corruption", "adequate resources for development", "adequate technical capacity", "elimination of political control in staff recruitment", and "adequate funding for infrastructure delivery" are the significant drivers of infrastructure delivery at the MMDAs. This study therefore recommends the establishment of efficient legal and institutional frameworks by the government to support and enhance the required capacities of the MMDAs for effective infrastructure delivery. The findings would help to address the infrastructural needs of local communities by presenting solutions to the challenges associated with infrastructure delivery which plague the MMDAs. Knowledge gained from this study could be applied to other similar developing countries pursuing decentralization as means to ensuring infrastructure delivery at the local government level.
\end{abstract}

\section{Keywords}

Drivers, Infrastructure, Delivery, Decentralisation, MMDAs 


\section{Introduction}

Decentralised infrastructure provision has been widely acknowledged as one of the most efficient local governance reforms for faster infrastructure delivery and economic growth (Ofori, 2012; Bardhan, 2002). It has also been identified as the major institutional framework responsible for the phenomenal industrial growth in most countries in South-Eastern Asia including China during the last two decades (Bardham, 2002). It is recognized that there is a very huge infrastructure gap in most developing countries in the Sub-Saharan African region which can be solved through effective implementation of decentralisation reforms. It is estimated that approximately US\$1.8 -2.3 trillion of annual infrastructure investment will be required to propel the economy of Sub-Saharan African nations (Frank \& Martinez-Vazquez, 2014). In recognition of the importance of decentralisation reforms as having the greatest potential of increasing government's response to the pro-poor (Azila-Gbettor et al., 2014), the World Bank endorsed decentralisation as a major reform on its agenda for faster and economic delivery of most of its sponsored infrastructure projects (World Bank, 2002). Decentralisation reforms in Ghana lag behind most of its competitors due to lack of commitment and stringent bureaucratic interference from central government agencies (Ministry of Local Government and Rural Development (MLGRD), 2010), who are not fully committed to the implementation of major reforms to ensure effective delivery of infrastructure by the MMDAs. Ghana however needs to address the problems associated with poverty, homelessness, streetism, rural-urban dynamics, by thriving to close the infrastructure gap that exists in order to achieve its objectives of meeting the sustainable development goals (SDGs). Frank and Martinez (2014) explained that over or undersupply of infrastructure is risky and can easily lead to wasteful spending of scarce resources. Adequacy of infrastructure helps a society to improve its citizen's standard of living, and is a fundamental prerequisite for economic growth and development.

Decentralisation has empowered people through popular participation, accountability, effectiveness and efficient provision of goods and services by MMDAs (Antwi, 2011). It is an important process that allows decongestion of the central government and reduces the workload to manageable proportions (Edoun \& Jahed, 2009). The District Assemblies (defined to include the Metropolitan Municipal and District Assemblies), under the 1992 Constitution of the Republic of Ghana and the Local Governance Act 2016 (Act 936), are assigned responsibilities which include the formulation and execution of plans, programmes and strategies for the effective mobilisation of the resources necessary for the overall development of the districts. According to the Works Departments Operational Manual (2018), the Works Departments, are however the bodies under the District Assemblies (DAs) that ensure the effective implementation of infrastructural works (building, water and feeder roads) related policies and programs at the local level. Infrastructure is very essential for the provision of public services and economic development of a nation (Williams, 2016). Nev- 
ertheless, ineffective delivery of infrastructure by the Works Departments may clearly be identified where majority of the MMDAs lack financial resources to undertake the development of decentralised infrastructure, and low human resource capacity to handle projects. The MMDAs in Ghana hardly fulfil their mandate of delivering economic and efficient infrastructure due to unclear or confused implementation of decentralisation (Frank \& Vazquez, 2014; Aigbavboa, 2014). They often lack the necessary internal engineering and technical expertise for efficient infrastructure delivery, and therefore usually outsource their engineering and technical capacity to the private sector (Professionals Australia \& Institute of Public Works Engineering Australia, 2015). Moreover, Frank and Vazquez (2014) identified the challenge of management inefficiencies among local governments resulting in poor delivery of decentralised infrastructure. The delivery of infrastructure by MMDAs is also challenged by the lack of political commitment of central government officials to decentralisation of infrastructure delivery (Robinson, 2007). The question arising from the issues raised above is, "what factors will drive infrastructure delivery at the Metropolitan, Municipal and District Assemblies in Ghana?". The purpose of this study therefore is, to assess drivers of infrastructure delivery by MMDAs in Ghana with the view to overcoming the challenges to infrastructure delivery at the local level and improving local development.

\section{Literature Review}

\subsection{Concept of Decentralised Infrastructure}

Infrastructure plays a key role in accomplishing many critical goals such as regional particularities, ethnic diversity, democratic local governance and the inability of central governments to reach the poverty-ridden communities (Serageldin et al., 2000). Craven (2017) defines infrastructure as essential facilities, services, and organisational structures for cities and communities. There are different ways of classifying infrastructure. They are divided into Network infrastructure which include roads, streets, bridges, electricity and water, and Point infrastructure such as hospitals and school buildings, which are more common to the social sectors (Frank \& Martinez-Vazquez, 2014). Technological advancements in the infrastructure sector have improved upon the efficiency of providing services for market areas and smaller jurisdictions. In many ways, these same forces are also driving the decentralisation of infrastructure services as a key to improving local conditions and critical component of local economic development (Serageldin et al., 2000). An econometric study in Europe for instance, recently found that decentralising revenue authority to subnational governments increased their investment in economic infrastructure, without reducing their social investment (Kappeler et al., 2013).

The provision of public infrastructure is one of the prime mandates of governments all over the world, and Ghana is not different. Infrastructure which includes roads, power, water, sanitation and airports, among others are the fun- 
damental prerequisite for economic growth and development. Studies across the world have consistently shown the close relationship between decentralised infrastructure and the strength of economic output (Magdalene, 2013). However, infrastructural provision at the grassroots faces serious challenges (Lawal, 2014). Decentralised provision of infrastructure is advocated for better matching of infrastructure services with local preferences and needs, and for enhancing efficiency and equity of public provision (Shah, 2014). Decentralised infrastructure delivery often requires the establishment of efficient institutional framework to ensure effective implementation (Bahl \& Bird, 2014), backed by experienced human resource in project development and delivery. Further, it is essential that effective implementation of decentralisation reforms considers the use of some local skilled technical/engineering staff, adopt sustainable procurement methods for works, as well as competent contracts management to account for quality and changes during execution of infrastructure projects. It should also be noted that, success in decentralisation implementation requires efficient coordination of all executive plans and policies within a clear and unambiguous legal and institutional framework for efficient delivery of quality infrastructure (Aigbavboa, 2014).

\subsection{Drivers of Decentralised Infrastructure Delivery}

Decentralisation holds great potential for development (Bossuyt \& Gould, 2000). It can ensure a more efficient allocation of resources (including development aid), enhance local resource mobilisation and improve local governance. One of the key propositions for decentralisation is its acclaimed ability to enhance revenue generation at the local level, provide infrastructure and thus, ensure that local governments are adequately resourced. With enough resources, decentralists believe, local government can provide the necessary infrastructure and services to ensure rapid poverty reduction. The aim of decentralisation is to re-design the governmental system in such a way that it can deliver services efficiently and effectively to the citizenry. Olum (2014) defines decentralisation as the process through which the central government transfers its powers, function, responsibility and finances, or decision-making power to other entities away from the centre to either lower levels of government, or dispersed central state agencies, or the private sector. The experience of decentralisation in Ghana for the development and improvement of administration under the District Assemblies' attempts have proved ineffective, inefficient and problematic (Amegashie-Viglo, 2004). Despite the fact that decentralised infrastructure delivery fosters faster infrastructure delivery and economic growth (Ofori, 2012), it is faced with numerous challenges that cripple the effort of local governments in their delivery of infrastructure. Nevertheless, there are issues that form the bedrock of comprehensive and systematic strategies which drive the delivery of decentralised infrastructure (Hossain, 2003). According to Scott (2009), political commitment is very key to enhancing the effective delivery of decentralised infrastructure. Gaining the support and commitment of central government officials for decentralisation is critical. Scott (2009) also identified the implementation of 
good infrastructural policies as one of the main drivers. He asserted that, local governments should be allowed to design and implement policies that address the peculiar needs of their areas. The local people should be involved in the formulation and implementation of these policies and projects (Lawal, 2014). People need to be consulted to know their needs before projects are initiated for them. It is appropriate for the people to determine what they need as this enhances their sense of belonging and claim of ownership of such projects. People's participation is one of the ingredients of good governance. Furthermore, Scott (2009) identified that the present monthly allocation from federal government to local government in Nigeria is grossly inadequate and suggested that local government fund should be increased. This will provide them with enough financial resources for proper infrastructure delivery. Nonetheless, undue interference from higher governments e.g. state and federal, should be minimised. The idea of imposition from state or federal government should be discouraged. Although they can be partners in progress, such partnership must bring meaningful development. According to Agyemang (2010), MMDAs in Ghana have legal rights to generate their own revenue. However, the funds they generate are insufficient to cater for their needs, thereby relying on the central government to finance most of their activities (Oduro, 2009). Frank and Martinez-Vazquez (2014) emphasized on flexible financial sources by the government to adjust the regulatory and assignment challenges. In order for MMDAs to effectively deliver decentralised infrastructure, there should be adequate resources available for development. Another driver of effective decentralised infrastructure delivery is adequate technical capacity. Technical capacity deals with the ability to use technological assets, and knowhow of engineering works. The extent to which technical capacity is clearly developed and focused in an organisation affects the way people can be utilized towards project delivery and development (Lampel, 2001). Checking corruption is also one of the effective approaches to improving decentralised infrastructure delivery which can be achieved by the delivery of right quality and quantity of infrastructural services. Corruption is a barrier to rural infrastructural development and must be severely punished so as to deter others from the act (Lawal, 2014).

\section{Research Methodology}

The research followed the quantitative approach. Quantitative methods allow for the use of structured questionnaire surveys, enabling researchers to generalize their findings from a sample of a population (Creswell, 2014). It is also appropriate for a research where the researcher has some information on his population. A survey using structured questionnaires was conducted to solicit data for the study. The questionnaire consisted of two parts namely demographic or background information of the respondents, and drivers of infrastructure delivery at the MMDAs in Ghana. The first part comprised the job position, academic qualification, and resident District Assembly (DA) of respondents as well as their years of working experience in the MMDAs. The criteria for selection of 
respondents for the study included, 1) possession of at least 5 years of working experience at the particular MMDA, 2) must be a professional with high degree of technical knowledge and understanding of the subject matter to be discussed, 3) must possess at least HND in construction-related profession, and 4) be willing to participate in the study. The second part had list of predetermined factors constituting drivers of infrastructure delivery by the MMDAs identified from the review of germane literature. The targeted population was professionals in the Department of Works (DoWs) of the various MMDAs within the Ashanti and Greater Accra Regions. The Greater Accra and Ashanti Regions of Ghana are viewed as the most urbanised, populated, and rapidly growing regions in Ghana, and hence, almost all infrastructure developmental activities are focused in these two regions (Sawe, 2018). The selection of the Greater Accra and Ashanti Regions of Ghana as units of analysis for the study was therefore appropriate, since the DoWs of the MMDAs within these regions are usually engaged with a lot of infrastructure projects and are endowed with construction professionals with enough practical experience in infrastructure delivery. The Departments of Works under the various MMDAs ensure the delivery of infrastructure and other developmental activities within their domain. Cluster sampling was used to divide the population since each region has its own number of Metropolitan, Municipal and District Assemblies. There is a total of 72 MMDAs from the 2 selected regions. For cluster sampling, the sample frame is the complete list of clusters rather that a complete list of individual cases with the population. The Metropolitan, Municipal and District Assemblies are mixed up, so there was the need to group them accordingly in order to afford each of them an equal chance of being selected. The Metropolitan Assembly category has the largest population size followed by the Municipal and District Assemblies in that order. All the clusters in the Metropolitan Assemblies of the two regions were selected for the study (i.e. Kumasi Metropolitan, Accra Metropolitan and Tema Metropolitan). A simple ratio sampling approach was, however, used to select Municipal and District Assembly cases from each of the 2 clusters (Greater Accra and Ashanti Regions). By employing the simple ratio format, the number 2 was selected as the common divisible factor to divide the total number of clusters at both $\mathrm{Mu}$ nicipal and District levels. Every 2nd, 4th, 6th, etc. within the clusters of the Municipal Assemblies (i.e., a total of 19) and District assemblies (i.e., a total of 14) were selected. Purposive sampling technique was employed to select a total of 150 professionals from the 36 MMDAs. Purposive sampling involves the use of the researcher's discretion to select a sample which per his understanding possesses the knowledge and expertise needed to provide the requisite information for the study (Greener, 2008). A total of 121 questionnaires were retrieved, constituting a response rate of 81 per cent. A retrieval rate of more than 50 per cent is considered acceptable and reliable (Yeboah \& Andrew, 2020). The data collected from the questionnaire survey was analyzed using mean scores and the one sample $\mathrm{t}$-test. 


\section{Results and Discussion}

\subsection{Demographic Characteristics of the Respondents}

The descriptive statistics of the demographics were studied to enable the researcher to evaluate the respondent's characteristics relevant to the study. This was done to enhance the understanding of the participants' profile and increase the degree of confidence in the data reliability and precision. According to Ahadzie (2007), the background information of respondents is required to authenticate the credibility of the data gathered. The aim of presenting the background data of respondents who take part in a study is to enhance the confidence in the reliability of the data collected (Kissi et al., 2017). The results of the background information of the respondents are presented as follows: 28 per cent of the respondents were Engineers, 26 per cent were Technical Officers, 17 per cent were Architects, 12 per cent were Quantity Surveyors, 12 per cent were Heads of Departments, 3 per cent of the respondents were Project Managers, whiles 2 per cent of the respondents were Estate Managers. The majority (41 per cent) of the respondents surveyed had an undergraduate degree. Thirty-seven (37) per cent of the respondents had a master's degree. The rest (22 per cent) had either HND or City and Guilds Certificates. Regarding the number of years spent in the MMDAs, 34 per cent of the respondents surveyed had more than 5 years' experience in the various MMDAs, 30 per cent had between 1 - 2 years working experience, whiles 29 per cent of the respondents had between 2 - 5 years working experience in the various MMDAs. Only 7 per cent had less than one year working experience in the MMDAs. It could be deduced from the background information of the respondents that, most of them were highly educated and had enough experience working in their respective MMDAs and hence, could provide reliable answers to the questionnaires.

\subsection{Drivers of Infrastructure Delivery at the MMDAs}

In analysing the drivers of infrastructure delivery at the MMDAs, mean scores were initially used. According to Cheng and Li (2002), the mean score ranking technique is used to test the significance of factors. A Likert scale of $1-5(1=$ least important and $5=$ most important) was used in the questionnaires to aid the respondents in rating their level of agreement to the drivers of infrastructure delivery A statistical test of the mean was conducted to determine whether the population considered a particular variable to be important or not. The mean for each variable with its corresponding standard deviation is presented in Table 1. All the means scores above 3.5 are considered as consistently agreed to by the respondents of the study as important. The significance level was set at $95 \%$ in accordance with the levels of risk. This is premised on the five-point Likert scale rating where a variable is deemed important if its mean was equal to or more than 3.5 (Field, 2005). From Table 1, twelve (12) factors were deemed important and ranked from most important to least important as: Effective managerial skills and proper supervision; Adequate funding for infrastructure delivery, 
Table 1. Drivers of infrastructure delivery at the MMDAs.

\begin{tabular}{lcccc}
\hline \multicolumn{1}{c}{ Drivers } & Mean & SD & Rank \\
\hline Effective managerial skills and proper supervision & 4.10 & 0.746 & $\mathbf{1}^{\text {st }}$ \\
Adequate funding for infrastructure delivery & 4.03 & 0.752 & $\mathbf{2}^{\text {nd }}$ \\
Attention to developing appropriate local authority procurement system & 3.87 & 0.763 & $\mathbf{3}^{\text {rd }}$ \\
Adequate technical capacity & 3.79 & 0.942 & $\mathbf{4}^{\text {th }}$ \\
Effective communication & 3.73 & 0.827 & $\mathbf{5}^{\text {th }}$ \\
Elimination of political control in staff recruitment & 3.73 & 0.885 & $\mathbf{6}^{\text {th }}$ \\
Proper cost budgeting & 3.71 & 0.779 & $\mathbf{7}^{\text {th }}$ \\
Checking corruption & 3.70 & 0.833 & $\mathbf{8}^{\text {th }}$ \\
Political commitment of central government & 3.69 & 0.938 & $\mathbf{9}^{\text {th }}$ \\
MMDAs must be autonomous in decision making in infrastructure delivery & 3.64 & 0.806 & $\mathbf{1 0}^{\text {th }}$ \\
Flexibility in the policy attached to central government funded projects & 3.58 & 1.086 & $\mathbf{1 1}^{\text {th }}$ \\
Implementation of good construction policies & 3.52 & 1.058 & $\mathbf{1 2}^{\text {th }}$ \\
Involvement of inhabitants' decisions & 3.45 & 0.966 & $\mathbf{1 3}^{\text {th }}$ \\
Adequate resources for development & 3.30 & 0.972 & $\mathbf{1 4}^{\text {th }}$ \\
\hline
\end{tabular}

Source: The Authors.

Attention to developing appropriate local authority procurement system; Adequate technical capacity; Effective communication; Elimination of political control in staff recruitment, Proper cost budgeting, Checking corruption; Political commitment of central government, MMDAs must be autonomous in decision making in infrastructure delivery, Flexibility in the policy attached to central government funded projects, and Implementation of good construction policies. However, two factors had mean scores less than 3.5 and therefore were deemed not important: Involvement of inhabitants decisions, and Adequate resources for development.

Furthermore, the one sample t-test was used to test the significance or otherwise of the factors as shown in Table 2. This was used in ascertaining whether a sample mean was significantly deviant from a hypothesised mean (Ahadzie, 2007). For a single sample test, its hypothesis was:

$$
\begin{aligned}
& H_{o}: U=U_{o} \\
& H_{a}: U<,>U_{o}
\end{aligned}
$$

with $H_{o}$ representing the null hypothesis, Ha representing the alternative hypothesis and $U_{o}$ representing the hypothesised mean. Ahadzie (2007) records that for a usual one sample t-test, the mean of the test group, degree of freedom for the test (an approximate of the sample size), the $\mathrm{t}$-value (strength of test) and the $P$-value (probability of test being significant) are usually reported. For each variable, the null hypothesis was that this variable was not significant (Ho: $U=U_{o}$ ). $U_{o}$ is the critical rating above which the variable is considered important. In this research, the higher ratings of 4 and 5 were chosen for the rating scale as important 
Table 2. One-sample test values for drivers of infrastructure delivery at the MMDAs.

\begin{tabular}{|c|c|c|c|c|c|c|}
\hline \multirow{3}{*}{ Drivers } & \multicolumn{6}{|c|}{ Test Value $=3.5$} \\
\hline & \multirow{2}{*}{$\mathrm{t}$} & \multirow{2}{*}{ Df } & \multirow{2}{*}{$\begin{array}{l}\text { Sig. (2-tailed) } \\
\text { or } p \text {-value }\end{array}$} & \multirow{2}{*}{$\begin{array}{c}\text { Mean } \\
\text { Difference- }\end{array}$} & \multicolumn{2}{|c|}{$\begin{array}{l}\text { 95\% Confidence Interval } \\
\text { of the Difference }\end{array}$} \\
\hline & & & & & Lower & Upper \\
\hline Effective managerial skills and proper supervision & 8.833 & 121 & 0.000 & 0.599 & 0.46 & 0.73 \\
\hline Political commitment of central government & 2.276 & 121 & 0.025 & 0.194 & 0.03 & 0.36 \\
\hline Effective communication & 3.024 & 121 & 0.003 & 0.227 & 0.08 & 0.38 \\
\hline Flexibility in the rule attached to central government funded projects & 0.795 & 121 & 0.428 & 0.079 & -0.12 & 0.27 \\
\hline Attention to developing appropriate local authority procurement system & 5.301 & 121 & 0.000 & 0.368 & 0.23 & 0.51 \\
\hline Proper cost budgeting & 2.975 & 121 & 0.004 & 0.211 & 0.07 & 0.35 \\
\hline Checking corruption & 2.673 & 121 & 0.009 & 0.202 & 0.05 & 0.35 \\
\hline Implementation of good construction policies & 0.215 & 121 & 0.830 & 0.021 & -0.17 & 0.21 \\
\hline Involvement of inhabitants' decisions & -0.612 & 121 & 0.542 & -0.054 & -0.23 & 0.12 \\
\hline Adequate resources for development & -2.292 & 121 & 0.024 & -0.202 & -0.38 & -0.03 \\
\hline MMDAs must be autonomous in decision making in infrastructure delivery & 1.861 & 121 & 0.065 & 0.136 & -0.01 & 0.28 \\
\hline Adequate technical capacity & 3.331 & 121 & 0.001 & 0.285 & 0.12 & 0.45 \\
\hline Elimination of political control in staff recruitment & 2.825 & 121 & 0.006 & 0.227 & 0.07 & 0.39 \\
\hline Adequate funding for infrastructure delivery & 7.797 & 121 & 0.000 & 0.533 & 0.40 & 0.67 \\
\hline
\end{tabular}

Source: The Authors.

and very important respectively, while $U_{o}$ was set at 3.5. In this study, the hypothesised mean is set at 3.5. This is for the reason that if $5=$ strongly agree, and 4 = agree, then for a variable to be consistently considered agreed, it should have a mean above the neutral point 3 . Hence the hypothesised mean was set between 3 and 4 (i.e. 3.5).

Based on Table 2, all factors that had positive t-values indicated that their mean scores were above the hypothesised mean of 3.5 and these were deemed significant and vice versa. $P$-values ranging from 0.01 to 0.05 imply that the alternative hypothesis is true, therefore significant results. $P$-values of above 0.05 show that the test is not statistically significant. The results of the one sample t-test at significance level of 0.05 or less indicate that, ten (10) factors out of the twelve (12) important factors (or 10 out of the 14 factors) are deemed significant. These include: Effective managerial skills and proper supervision (0.000); Political commitment of central government (0.025); Effective communication (0.003); Attention to developing appropriate local authority procurement system (0.000); Proper cost budgeting (0.004); Checking corruption (0.009); Adequate resources for development (0.024); Adequate technical capacity (0.001); Elimination of political control in staff recruitment (0.006); and Adequate funding for infrastructure delivery $(0.000)$. The results further indicate that, four factors with $P$-values more than 0.05 were deemed not significant: Flexibility in the rule at- 
tached to central government funded projects (0.428), Involvement of inhabitants' decisions (0.542), MMDAs must be autonomous in decision making in infrastructure delivery (0.065), and Implementation of good construction policies (0.830). The significant variables are discussed as follows:

\section{Adequate technical capacity}

Adequate technical capacity had a $P$-value of 0.001 and therefore considered significant. The findings indicate that, adequate technical capacity is a key driver of effective infrastructure delivery by MMDAs in Ghana. This finding is consistent with Robinson (2007), who indicated that decentralised provision of services often requires a high level of technical capacity. Robinson (2007) further stated that not only does technical capacity improve the performance of local officials, but also influences their behaviour towards service users. Technical capacity deals with the ability to use technological assets and knowhow on engineering works. The extent to which technical capacity is clearly developed and focused in an organisation affects the way human resource can be utilised towards project delivery and development (Lampel, 2001). It is not only institutional authority that matters, but the capacity of local governments to respond to demands. In many cases, staff training and basic administrative infrastructure is severely lacking (Deininger \& Mpuga, 2005). In order to enhance the effective delivery of decentralised infrastructure, the MMDAs in Ghana must possess the requisite technical capacity for infrastructure delivery.

\section{Elimination of political control in staff recruitment}

Elimination of political control in staff recruitment had a $P$-value of 0.006 and therefore significant. This finding suggests that MMDAs can better deliver decentralised infrastructure when politicians do not interfere with the recruitment of their staff. MMDAs must take centre stage in the recruitment of their staff. Staff recruitments in the MMDAs must be devoid of political biases where party favourites with little or no knowledge in the job role for recruitment are hired (Mohammed, 2018; Lewis, 2007). The recruitment of personnel under the MMDAs should be decentralised, meaning the MMDAs should be allowed to recruit and cater for their staffing needs which is more efficient. Nevertheless, there must be the provision of qualified personnel. It is appropriate for the various MMDAs to be offered autonomy in staff recruitment to determine the personnel that they lack and make the necessary recruitments so as to help in their delivery of infrastructure.

\section{Adequate funding for infrastructure delivery}

Adequate funding for the delivery of infrastructure had a $P$-value of 0.000 and hence significant. Robinson (2007) indicated that the lack of funding leads to poor delivery of public services. Therefore, the equity, quality and efficiency of infrastructure delivery largely depend on the adequacy of funding. According to Scott (2009), local government funds should be increased. Currently, many local governments in developing countries face the near impossible task of funding infrastructure and services required to meet the basic needs of the growing pop- 
ulations. Local governments frequently suffer from inadequate technological infrastructure and capacity, and opportunities for revenue generation are often restricted by inadequate regulatory frameworks or disadvantageous political structures (United Nations Human Settlements Programme, 2015). However, strategic governance and financing systems can provide hope for struggling local governments. In view of this, appropriate financial management systems can tap into strategies that improve efficiency of revenue collection or internally generated funds, which would in turn enhance the effective delivery of infrastructure.

\section{Effective managerial skills and proper supervision}

Effective managerial skills and proper supervision had a $P$-value of 0.000 and therefore significant. This implies that effective managerial skills and proper supervision is one of the key drivers of effective infrastructure delivery by MMDAs in Ghana. Formal processes for monitoring and supervision must be followed in the delivery of infrastructure (Ayee \& Crook, 2003). On the part of the MMDAs, contractors and other service providers on public projects must be strictly monitored and supervised on their performance. There is the need to train local government staff to equip them with the necessary managerial skills and capacity for decentralised infrastructure delivery (Berlan \& Shiffman, 2012). Hence, MMDAs should organize frequent training programs for their staff to help improve their skills and competence for effective infrastructure delivery. Effective managerial skills and proper supervision will ensure performance disciplines on these projects, thereby enhancing the effective delivery of decentralised infrastructure.

\section{Political commitment of central government}

Political commitment of central government had a $P$-value of 0.025 . The study identifies the political commitment of central government as a significant driver of effective infrastructure delivery by MMDAs in Ghana. This finding agrees with Robinson (2007) who asserted that, political commitment and leadership of central government are intrinsically significant to the delivery of decentralised infrastructure. Gaining the support and commitment of central government officials for decentralisation is very critical. The MMDAs need the capacity and political will to implement reforms that will favour their respective jurisdictions. Officials and politicians at the central government level need to understand and support the MMDAs concerning the investments which will be most effective in meeting the needs of the inhabitants. The central government's political commitment to the democratic empowerment of local governments can lead to a successful pro-poor decentralisation (Robinson, 2007; Heller, 2001), and in turn the effective delivery of decentralised infrastructure.

\section{Effective communication}

Effective communication had a $P$-value of 0.003 and therefore significant. Effective communication is a success factor of quality of infrastructure delivery. According to East Asia Forum (2015), effective communication ensures that public initiatives taken are often in the right direction. Effective communication 
with contractors and other stakeholders on infrastructure projects would eliminate the instances where they make assumptions which can ultimately affect the timely delivery of the project, as well as its cost and quality. This can drive the effective delivery of decentralised infrastructure by the MMDAs. Furthermore, efficient coordination and mechanisms for information sharing must be established at various local government levels to ensure effective communication of information for the effective delivery of decentralised infrastructure (Asia-Pacific Leadership and Policy Dialogue for Women's and Children's Health, 2012). Enhanced communication processes are also necessary to facilitate community acceptance of the need for major projects in the country.

Attention to developing appropriate local authority procurement system

Attention to developing appropriate local authority procurement system had a $P$-value of 0.000 and therefore significant. Attention to developing appropriate local authority procurement system is a significant driver of effective decentralised infrastructure delivery by MMDAs in Ghana. In decentralised infrastructure provision, the procurement process is the most critical step. Procurement process is one of the elements that helps in making construction projects successful. Therefore, sufficient attention should be given nationwide to the development of appropriate local authority procurement systems and capacities for efficient decentralised infrastructure delivery. The method of procurement employed is also an important part of the procurement process, because it determines the processes to be monitored in acquiring works, goods and services from invitation and submission of tenders, through evaluation, to the award of contract. The procurement process in selecting a suitable contractor and other service providers must be devoid of political influences, but rather adherence must be made to the laid down rules of the procurement system.

\section{Proper cost budgeting}

Proper cost budgeting had a $P$-value of 0.004 and therefore significant. Proper cost budgeting, according to the findings of the study, is a significant driver of effective decentralised infrastructure delivery by the MMDAs in Ghana. It is one of the essentials to delivering quality infrastructure. Cost budgeting involves estimating in detail for all the costs of activities and resources of a project. This makes it possible to track (i.e. measure and evaluate) the cost performance of a project. Frank and Martinez-Vazquez (2014) asserted that, proper cost budgeting helps in matching requirements which are typically used to reveal the policy preferences of the recipient, and for effective co-funding and risk sharing for infrastructure delivery. Since the MMDAs rely on funding from the central government or the other relevant sources, they need to have firm cost budgets. To ensure the effective delivery of decentralised infrastructure by the MMDAs, proper cost budgets or plans must be prepared to ensure that there are sufficient funds available for them to execute infrastructural projects.

\section{Checking corruption}

Checking corruption had a $P$-value of 0.009 and therefore significant. Check- 
ing corruption is one of the effective approaches of enhancing the effective delivery of decentralised infrastructure. Corruption as a way of life must be deterred and carefully checked in the country. It must be severely punished to serve as deterrence to others, as this remains the only antidote to rural infrastructural problem to improve development (Lawal, 2014). In order to actualize the expected economic gains of infrastructural projects, Osei-Tutu et al. (2010) conducted a study to explore and discuss as well as address prevalent corruption practices in public procurement of infrastructural projects in Ghana. They identified that the most inherent corruption practices in the Ghanaian infrastructure projects delivery system were conflict of interest, bribery, embezzlement, kickbacks, tender manipulation and fraud. Owusu et al. (2019), by virtue of a review of anti-corruption measures to check corruption in construction project management, identified that ethical codes, transparency mechanism, training and development initiatives were the predominant anti-corruption measures. The effective delivery of decentralised infrastructure by the MMDAs requires the establishment of strong anti-corruption strategies to check corruption practices that occur during the delivery of infrastructural projects. Furthermore, according to Osei-Tutu et al. (2010), checking corruption demands the existence of a strong political will and commitment by the government to mitigate the incidence of corruption practices.

\section{Adequate resources for development}

Adequate resources for development had a $P$-value of 0.024 and therefore significant. Adequate resource for development is very essential for the effective delivery of infrastructure at the MMDAs. Provision of cultural and modern facilities deals with the improvement of transportation and information technology infrastructure to help them compete internationally and locally. Also, businesses are also looking for services that will attract the knowledge workers services that enhance the quality of life in the city such as parks and recreation based on cultural facilities (United Nations Human Settlements Programme, 2015). This determines the effective measures of improving cultural approach to infrastructure delivery by the Department of Works of the MMDAs in Ghana.

\section{Implications of the Findings}

There is not much empirical evidence with regards to studies on drivers of decentralised infrastructure delivery. This study, by virtue of its findings, fills the relevant gap in literature and contributes substantially to existing knowledge on decentralisation and local governance. The findings of this study would also help to address the infrastructural needs of the local people by presenting solutions to challenges associated with decentralised infrastructure delivery which plague the MMDAs. The outcome of the study would provide actors at the local level with insights into factors that enhance decentralised infrastructure delivery, in their quest to improve the standard of living of the local people. Furthermore, in terms of policymaking, the findings would enhance the development of efficient 
institutional frameworks that would ensure the effective delivery of infrastructure by MMDAs in Ghana. The empirical aspects of this study were entirely based on the experiences of the Ghanaian construction industry and hence, practical experiences from construction professional across the world might differ. Furthermore, the study was conducted in the Greater Accra Region and Ashanti Region, hence, the same experiences may not apply to the other remaining regions. Although it can be said that some of the experiences shared by the respondents might be similar to the remaining regions and other African countries, this limitation does not in any way undermine the validity of the research undertaken and the potential application of its findings in other developing countries.

\section{Conclusion}

This study adopted the quantitative research approach as it sought to assess the drivers of decentralised infrastructure delivery by MMDAs in Ghana. A structured questionnaire survey was conducted to assess drivers of decentralised infrastructure delivery by the MMDAs. One hundred and twenty-one (121) professionals purposively selected from thirty-six (36) MMDAs in the Greater Accra and Ashanti regions of Ghana participated in a questionnaire survey. The statistical tools used for the analysis of the data collected were mean scores, standard deviation and one sample t-test. The findings of the study indicate that the ten most significant drivers of decentralised infrastructure delivery by MMDAs are: Effective managerial skills and proper supervision; Political commitment of central government; Effective communication; Attention to developing appropriate local authority procurement system; Proper cost budgeting; Checking corruption; Adequate resources for development; Adequate technical capacity; Elimination of political control in staff recruitment; and Adequate funding for infrastructure delivery. The study reveals that, delivery of infrastructure by the MMDAs can be improved by ensuring political commitment of the central government officials to implementing decentralisation reforms, limiting interference from central government, providing adequate financial resources, enhancing the technical capacities of the MMDAs, among others. Per the findings of the study, the MMDAs in Ghana should be provided with the needed capacity (adequate funding, competent staff and autonomy) to enable them to deliver decentralised infrastructure effectively. In view of this, it is recommended that, legal and institutional frameworks need to be properly established by the government to support or enhance the required MMDAs' capacities for effective decentralised infrastructure delivery. By identifying factors that drive infrastructure delivery at the MMDAs in Ghana, challenges associated with infrastructure delivery at the local level could be easily overcome, to enhance local development. Knowledge gained from this study could be applied to other similar developing countries pursuing decentralization as means to ensuring infrastructure delivery at the local government level. 


\section{Conflicts of Interest}

The authors declare no conflicts of interest regarding the publication of this paper.

\section{References}

Agyemang, M. (2010). An Investigation into the Effects of Ghanaian Decentralized Development Planning System in the Provision of Health and Educational Infrastructure: The Case of the New Juaben Municipality. Doctoral Dissertation.

Ahadzie, D. K. (2007). A Model for Predicting the Performance of Project Managers in Mass House Building Projects in Ghana. PhD Thesis, Wolverhampton: School of Engineering and the Built Environment, University of Wolverhampton.

Aigbavboa, C. O. (2014). An Integrated Beneficiary Centred Satisfaction Model for Publicly Funded Housing Schemes in South Africa. Doctoral Dissertation, Johannesburg: University of Johannesburg.

Amegashie-Viglo, S. (2004). Decentralisation as a Strategy for Development. Research on Humanities and Social Sciences, 4, 2-3.

Antwi, E. K. (2011). Decentralisation a Tool for Grassroot Development: A Case of Asutifi District. Doctoral Dissertation, Kumasi: Institute of Distance Learning, Kwame Nkrumah University of Science and Technology.

Asia-Pacific Leadership and Policy Dialogue for Women's and Children's Health (2012). Effective Management of Decentralised Health Systems.

Ayee, J. R. A., \& Cook, R. C. (2003). “Toilet Wars”: Urban Sanitation Services and the Politics of Public-Private Partnerships in Ghana. IDS Working Paper No. 213, Brighton: Institute of Development Studies at the University of Sussex.

Azila-Gbettor, E. M., Adjimah, H. P., \& Tibu, S. K. (2014). Fiscal Decentralisation and Poverty Reduction: Citizens View. Journal of Social Economics Research, 1, 118-128.

Bahl, R., \& Bird, R. (2014). Decentralisation and Infrastructure in Developing Countries: Reconciling Principles and Practice. IMFG Papers on Municipal Finance and Governance, 14 .

Bardhan, P. (2002). Decentralization of Governance and Development. Journal of Economic Perspectives, 16, 185-205. https://doi.org/10.1257/089533002320951037

Berlan, D., \& Shiffman, J. (2012). Holding Health Providers in Developing Countries Accountable to Consumers: A Synthesis of Relevant Scholarship. Health Policy and Planning, 27, 271-280. https://doi.org/10.1093/heapol/czr036

Bossuyt, J., \& Gould, J. (2000). Decentralisation and Poverty Reduction: Elaborating the Linkages. Policy Management Brief, 12.

Cheng, E. W., \& Li, H. (2002). Construction Partnering Process and Associated Critical Success Factors: Quantitative Investigation. Journal of Management in Engineering, 18, 194-202. https://doi.org/10.1061/(ASCE)0742-597X(2002)18:4(194)

Craven, J. (2017). The Importance of Infrastructure.

Creswell, J. W. (2014). Research Design: Qualitative, Quantitative, and Mixed Methods Approaches (4th ed.). Los Angeles, CA: Sage.

Deininger, K., \& Mpuga, P. (2005). Does Greater Accountability Improve the Quality of Public Service Delivery? Evidence from Uganda. World Development, 33, 171-191. https://doi.org/10.1016/j.worlddev.2004.09.002

East Asia Forum (2015). Indonesia’s Infrastructure Progress Is Thwarted by Its Decentra- 
lised Structure.

Edoun, E. I., \& Jahed, M. (2009). The Merits of Decentralisation and Local Economic Development in South Africa. Pretoria: Global Action for Africa's Development.

Field, A. (2005). Factor Analysis Using SPSS. Retrieved March, 17, 63-71.

Frank, J., \& Martinez-Vazquez, J. (2014). Decentralisation and Infrastructure: From Gaps to Solutions. Atlanta, GA: International Center for Public Policy. https://doi.org/10.4324/9781315694108

Greener, S. (2008). Business Research Methods. Frederiksberg: Ventus Publishing.

Heller, P. (2001). Moving the State: The Politics of Democratic Decentralization in Kerala, South Africa, and Porto Alegre. Politics \& Society, 29, 131-163. https://doi.org/10.1177/0032329201029001006

Hossain, A. (2003). Administrative Decentralisation: A Framework for Discussion and Its Practices in Bangladesh.

Kappeler, A., Solé -Ollé, A., Stephan, A., \& Välilä, T. (2013). Does Fiscal Decentralisation Foster Regional Investment in Productive Infrastructure? European Journal of Political Economy, 31, 15-25. https://doi.org/10.1016/j.ejpoleco.2013.03.003

Kissi, E., Boateng, E. B., Adjei-Kumi, T., \& Badu, E. (2017). Principal Component Analysis of Challenges Facing the Implementation of Value Engineering in Public Projects in Developing Countries. International Journal of Construction Management, 17, 142-150. https://doi.org/10.1080/15623599.2016.1233088

Lampel, J. (2001). The Core Competencies of Effective Project Execution: The Challenge of Diversity. International Journal of Project Management, 19, 471-483.

https://doi.org/10.1016/S0263-7863(01)00042-4

Lawal, T. (2014). Local Government and Rural Infrastructural Delivery in Nigeria. International Journal of Academic Research in Business and Social Sciences, 4, 139. https://doi.org/10.6007/IJARBSS/v4-i4/771

Lewis, D. E. (2007). Testing Pendleton's Premise: Do Political Appointees Make Worse Bureaucrats? The Journal of Politics, 69, 1073-1088. https://doi.org/10.1111/j.1468-2508.2007.00608.x

Magdalene, A. (2013). Ghana Steps Up Infrastructure Investment. World Finance.

Ministry of Local Government and Rural Development (MLGRD) (2010). Decentralisation Policy Framework: Theme, Accelerating Decentralisation and Local Governance for National Development. Accra: Ministry of Local Government and Rural Development.

Mohammed, A. W. A. (2018). Politics in Decentralisation: The Appointment of Metropolitan, Municipal and District Chief Executives (MMDCEs) in Ghana. Advances in Social Sciences Research Journal, 5, 570-588. https://doi.org/10.14738/assrj.512.4675

Oduro, O. (2009). Challenges Facing Decentralisation in Ghana. The Decentralisation Agenda, 10, 6.

Ofori, G. (2012). Developing the Construction Industry in Ghana. The Case for a Central Agency. Singapore: Singapore University Press.

Olum, Y. (2014). Decentralisation in Developing Countries: Preconditions for Successful Implementation. Commonwealth Journal of Local Governance, No. 15, 23-38. https://doi.org/10.5130/cjlg.v0i0.4061

Osei-Tutu, E., Badu, E., \& Owusu-Manu, D. (2010). Exploring Corruption Practices in Public Procurement of Infrastructural Projects in Ghana. International Journal of Managing Projects in Business, 3, 236-256. https://doi.org/10.1108/17538371011036563 
Owusu, E. K., Chan, A. P., De-Graft, O. M., Ameyaw, E. E., \& Robert, O. K. (2019). Contemporary Review of Anti-Corruption Measures in Construction Project Management. Project Management Journal, 50, 40-56. https://doi.org/10.1177/8756972818808983

Professionals Australia \& Institute of Public Works Engineering Australasia (2015). Building Victoria Together: Improving the Infrastructure Delivery Capacity of Local Government.

Robinson, M. (2007). Does Decentralisation Improve Equity and Efficiency in Public Service Delivery Provision?

Sawe, B. E. (2018). Biggest Cities in Ghana. WorldAtlas.

Scott, Z. (2009). Decentralisation, Local Development and Social Cohesion: An Analytical Review. GSDRC Research Paper, 5.

Serageldin, M., Kim, S., \& Wahba, S. (2000). Decentralisation and Urban Infrastructure Management Capacity (pp. 1-2). The Third Global Report on Human Settlements.

Shah, A. (2014). Decentralised Provision of Public Infrastructure and Corruption.

United Nations Human Settlements Programme (2015). The Challenge of Local Government Financing in Developing Countries. Nairobi.

Williams, M. (2016). Variation in Infrastructure Delivery and Management Quality among Ghana's Local Governments (Project Memo). London: International Growth Centre.

Works Departments Operational Manual (2018). Local Government Service (LGS). Establishment, Operationalization and Management for the Metropolitan, Municipal and District Assemblies (MMDAs).

World Bank (2002). State and Local Governance in Nigeria. Sector Report No. 24477, Washington DC: World Bank.

Yeboah, E. N., \& Andrew, M. (2020). Challenges Faced by Metropolitan, Municipal, and District Assemblies (MMDAs) in Internal Revenue Mobilization in Ghana. International Journal of Asian Social Science, 10, 68-80.

https://doi.org/10.18488/journal.1.2020.101.68.80 